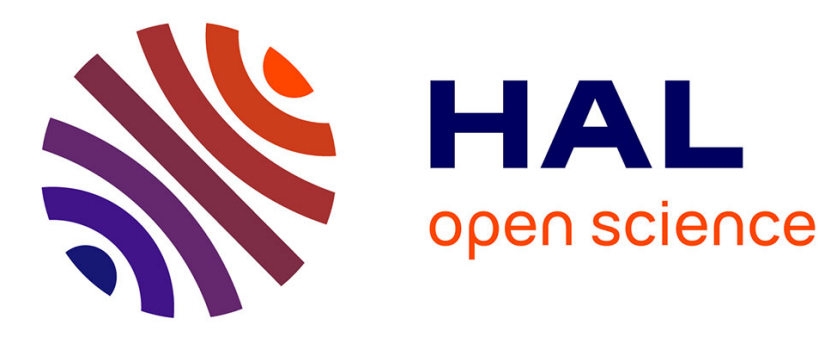

\title{
Identification of the state of suspension elements in railway systems
}

\author{
Ronald Martinod, German René Betancur, Leonel F Castañeda
}

\section{To cite this version:}

Ronald Martinod, German René Betancur, Leonel F Castañeda. Identification of the state of suspension elements in railway systems. Vehicle System Dynamics, 2012, 50 (7), pp.1121-1135. 10.1080/00423114.2012.656657 . hal-02182242

\section{HAL Id: hal-02182242 \\ https://hal.science/hal-02182242}

Submitted on 16 Jul 2019

HAL is a multi-disciplinary open access archive for the deposit and dissemination of scientific research documents, whether they are published or not. The documents may come from teaching and research institutions in France or abroad, or from public or private research centers.
L'archive ouverte pluridisciplinaire $\mathbf{H A L}$, est destinée au dépôt et à la diffusion de documents scientifiques de niveau recherche, publiés ou non, émanant des établissements d'enseignement et de recherche français ou étrangers, des laboratoires publics ou privés. 


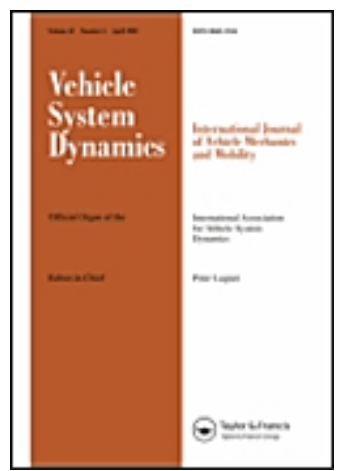

\section{Identification of the technical state of suspension elements in railway systems}

\begin{tabular}{|c|c|}
\hline Journal: & Vehicle System Dynamics \\
\hline Manuscript ID: & NVSD-2011-0096 \\
\hline Manuscript Type: & Original Paper \\
\hline $\begin{array}{r}\text { Date Submitted by the } \\
\text { Author: }\end{array}$ & 04-May-2011 \\
\hline Complete List of Authors: & $\begin{array}{l}\text { Castañeda, Leonel; EAFIT University, Mechanical Engineering } \\
\text { Martinod, Ronald; EAFIT University, Mechanical Engineering } \\
\text { Betancur, German; EAFIT University, Mechanical Engineering }\end{array}$ \\
\hline Keywords: & $\begin{array}{l}\text { IRF, LSCE, OMA, multi-body model, railway testing, stabilization } \\
\text { diagram }\end{array}$ \\
\hline
\end{tabular}

\section{SCHOLARONE ${ }^{m}$ Manuscripts}




\title{
Identification of the state of suspension elements in railway systems
}

\author{
R.M. Martinod ${ }^{a}$, G.R. Betancur ${ }^{a}$ y L.F. Castañeda $a^{a^{*}}$ \\ ${ }^{a}$ Mechanical Engineering Department, GEMI Research Group, EAFIT University, \\ Medellín, Colombia \\ Ronald Mauricio Martinod ${ }^{a}$ \\ E.mail: rmartino@eafit.edu.co \\ Adress: Carrera $49 \mathrm{~N}^{\circ} 7$ Sur 50 of. 14-203, Medellín (Colombia - South America) \\ Phone number: (57) (4) - 2619500 ext. 9896 \\ Germán René Betancur ${ }^{a}$ \\ E.mail: gbetanc4@eafit.edu.co \\ Adress: Carrera $49 \mathrm{~N}^{\circ} 7$ Sur 50 of. 14-203, Medellín (Colombia - South America) \\ Phone number: (57) (4) - 2619500 ext. 9896 \\ Leonel Francisco Castañeda Heredia ${ }^{a^{*}}$ \\ E.mail: 1casta@eafit.edu.co \\ Adress: Carrera $49 \mathrm{~N}^{\circ} 7$ Sur 50 of. 3-313, Medellín (Colombia - South America) \\ Phone number: (57) (4) - 2619500 ext. 9368
}

\footnotetext{
*Corresponding author. Email: 1casta@eafit.edu.co
} 


\section{Identification of the state of suspension elements in railway systems}

The running safety and passenger comfort levels in a vehicle are tightly related to the technical state of the suspension elements. The technical state of the suspension depends of the service life time as its components become old and wear out. A study on the dynamic behavior of a railway vehicle is established in relation to the damping elements in one of its suspension stages. An experimental measurement model is developed, obtaining a set of useful signals for the identification of the dynamic parameters of the vehicle and developing a test through the application of the OMA technique, using LSCE method as a basis to validate the numeric model of the multi-body system. Then, the study focuses on developing numeric simulations for the identification of the technical state of the dampers by the registration of dynamic variables under commercial service conditions and on estimating the state of the suspension elements.

Keywords: IRF, LSCE, multi-body model, OMA, railway testing, stabilization diagram.

\section{Introduction}

The modal properties of a dynamic system are traditionally obtained using techniques known as Experimental Modal Analysis (EMA). EMA techniques have been widely documented [1-3], nonetheless, for many cases relative to civil and mechanical structures it is difficult to apply the excitation with an impact hammer, shaker, etc. due to the size, shape, fragility or location [4].

For systems with auto-motion (aircraft, automobile, ship, train, etc.) it is necessary to know the modal parameters under normal running conditions, considering the particular characteristics of: bounder condition, distribution of forces in the frequency domain and level of response [5]; these systems posses normal operating condition which are difficult to reproduce in a laboratory, for which it is necessary to measure the physical and modal parameters during the operation.

The Operational Modal Analysis technique (OMA) is only based on the measurement of the response signals and uses the environmental excitations as nonmeasured signals [6]. OMA is used for the modal identification with high precision 
under typical operating conditions [7]. The following are some of OMA main advantages:

- It is possible to submit to this test systems whose excitation through the application of artificial external forces do not allow to obtain correct measurements; there are mechanic systems (e.g. freight train, suburban train, tramway) for which the sources of excitation (creepage phenomenon in the contact patch on the wheel-rail interface) can not be measured individually in a precise way, and as a result an erroneous modal model is obtained [8]. The only parameters that can be measured in an exact way are the response data [9].

- In situ tests can be developed without interruption and in parallel with other applications. It is not necessary to move the system to a laboratory to realize the tests under controlled conditions. In situ tests avoid the need of having an express test bank [10]. In consequence, it avoids the system to be submitted to inactive time.

- It is a simple test procedure similar to the Operating Deflection Shapes (ODS) technique, which employs a reference transducer and various mobile response transducers. OMA does not use reference transducers in the case where all the responses are measured synchronously; on the other case, one or some transducers are used depending on the number of repeated roots that are obtained. Any of the measurements can be employed as reference, which means that OMA is a Multiple-Input Multiple-Output (MIMO) technique and allows to estimate very proximal modes with high precision $[8,10]$. 
A technique (see Figure 1(a)) has been adopted for the evaluation of the technical state of the dampers through the measurement of variables under operating conditions of the vehicle using the OMA-LSCE method, this meaning with the excitations of the operating conditions which originate from uncontrolled sources. The present work exposes the steps to be followed in order to identify the technical state of the suspension elements.

Using the properties upon which the natural excitation technique [11] is based, the response functions of random noise can be used to determine the Impulse Response Function (IRF). The modal parameters of the system can be identified using standard identification methods in time domain [10]. In this paper the Least-Squares Complex Exponential method (LSCE) will be used.

LSCE is an OMA method in time domain whose procedure is illustrated in Figure 1(b). LSCE method determines the relation between the IRF in a Multiple Degrees of Freedom (MDoF) system, its complex poles and residues through a complex exponential. The IRF can be derived from the inverse Fourier transform (FT) for a Frequency Response Function (FRF) through the Random Decrement process (RD), or other methods. An Auto-Regressive model (AR) is constructed by the relation between poles and residues; the AR model solution allows to define a polynomial in whose roots are the complex roots of the system. Having established the roots (equivalent to the natural frequencies $\Omega$ and the damping rates $\xi$ ), the residues can be derived through the AR model and then obtain the modal shapes $\phi$ [2]. 
The inverse Lapace transform of the transfer function of a MDoF system is the IRF, $\mathbf{h}_{\mathbf{k}}$. This gives as a result a series of equally spaced time intervals $k \Delta(k=0,1$, $\ldots, 2 \mathrm{~N})$, then it is possible to express IRF as

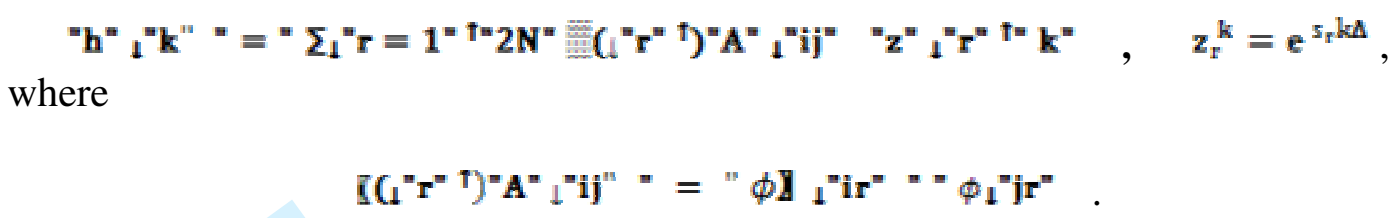

This expression is the product of the $\mathrm{i} t h$ and $\mathrm{j}$ th elements in the modal shape $\mathrm{r} t h[\phi]_{\mathrm{r}}$ and is named as the modal constant. The values in the series belong to the real numbers even if the residues and the roots $s_{\mathrm{r}}$ are complex values. It is possible to demonstrate that all imaginary parts will cancel each other because of the complex

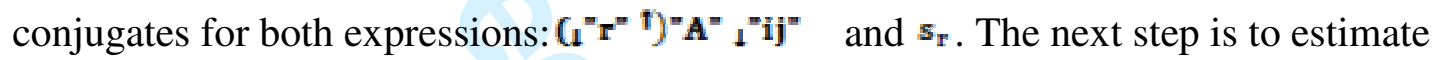
the roots and the residues for the sampled data. This solution is aided by the conjugacy of the roots $\mathbf{s}_{\mathrm{r}}$, therefore $\mathbf{z}_{\mathrm{r}}$. Mathematically, this means that $\mathbf{z}_{\mathrm{r}}$ are the roots of a polynomial with only real coefficients [4]

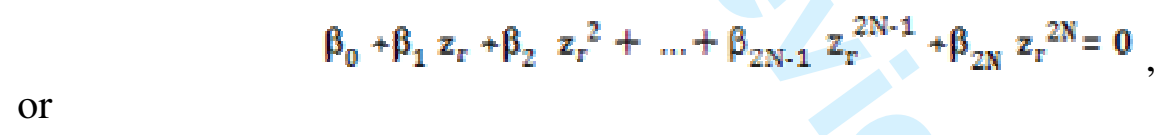$$
\beta_{0}+\beta_{1} z_{\mathrm{r}}+\beta_{2} z_{\mathrm{r}}^{2}+\ldots+\beta_{2 \mathrm{~N}-1} \mathrm{z}_{\mathrm{r}}^{2 \mathrm{~N}-1}+\beta_{2 \mathrm{~N}} z_{\mathrm{r}}^{2 \mathrm{~N}}=0
$$

or

This equation is known as the Prony equation. The coefficients can be estimated by the IRF values.

With the calculation of the system poles, it is possible to build the stabilization diagram, which allows to graphically represent the poles of a system when it is excited in one point (reference) and measurements are made in another one (responses) [12]. The poles are codified with alphanumeric characters: stable pole (s), vibration frequency and modal vector are stable (v), vibration frequency and stifling are stable (d), only stable the vibration frequency (f), and unstable pole (o). Once the poles have been selected it is possible to estimate the vibration shapes [13]. 
\{Figure 1\}

\section{Description of the object of study}

The study is applied to passengers' vehicles belonging to the massive transport railway vehicle fleet of Medellin city (Colombia), which is a railway system similar to suburban trains. Original equipment manufacturer of rolling stock was MAN for mechanical components and Siemens for electrical components. MAN has since become Adtranz company and subsequently Bombardier Transportation. The vehicles are similar in geometry and design to the ET420 train sets formerly operated by Deutsche Bahn in commuter service (e.g. the Munich S-Bahn) [4, 14].

The railway system has 42 three-unit cars (see Figure 2(a)). Each car has two (2) bogies that are supported over two (2) axle-wheel sets. Each car has a suspension of two (2) stages: primary and secondary [14, 15].

The primary suspension stage is composed by elastic and damping elements that connect the axle-wheel to the bogie (helicoidal springs, guide leafs and vertical dampers); the secondary suspension stage connects the bogie to the carbody (pneumatic spring, traction link, vertical and transversal dampers).

The end cars are powered, while the center unit is an unpowered trailer car. The end cars bogies have a DC motor located in transversal position, partially suspended over the axle and over an elastic suspension connected to the bogie frame, there is one $205 \mathrm{~kW}$ motor per axle $[14,16]$.

An EMA technique [4] has been used to determine de behavior of the vehicle under a given operating condition. EMA technique is applied to a set of tests based on the excitation and the response measurement of the vehicle, according to the theory on 
the classic modal analysis. The excitation of the vehicle is achieved by a manual inputs applied directly to the carbody, in the location and direction necessary to induce a specific shape mode. In order to be able to generate the excitation it is necessary to remove the damping elements of the vehicle suspension, condition denominated $\epsilon_{0}$ that allows the carbody to be excited by hand.

To obtain a better capture of the signals in the transducers (accelerometers) [17], these have been located at the ends of the carbody, collinear to the longitudinal plane of the carbody. The data is realized with a minimum sample frequency of $50 \mathrm{~Hz}$ [13].

The set of recorded signals is transformed to the frequency domain through FFT algorithm to obtain the characteristic frequencies of the carbody, finding the corresponding modal shape $[4,18,19]$. Table 1 shows the results obtained from EMA technique.

This work focuses on the study of the vehicle dynamic response [11], which is influenced by the technical state of the four (4) identical vertical dampers that each car has, $\delta_{j}$ with $j=1, \ldots, 4$ (see Figure $2(b)$ ). This type of component is characterized by a set of physical laboratory tests. The test's method requires the application of cyclical displacement excitation (sinusoidal) in determined ranges of frequency and peak-to-peak amplitudes $[4,15,19]$. The relation obtained from the characterization of the element is denominated nominal damping function, $\varepsilon_{10}$. From $\epsilon_{10}$, a set of nine (9) hypothetical properties are established, $\epsilon_{i}$ with $i=1, \ldots, 9$. The hypothetical properties have a similar behavior to $\epsilon_{10}$, but affected by a coefficient that reduces de damping property of the element $\delta_{j},{ }^{\mathbb{i}}=\frac{\mathbf{i}}{10} \mathbb{1 0}_{10}$. This is how the different technical 
states of the component are represented, causing a progressive degradation of the damping function. (Figure 2(c)).

\{Figure 2\}

$\{$ Table 1$\}$

Three (3) hypotheses are established in relation to the state of the suspension elements $\delta_{j}$, which is defined parametrically by the progressive degradation of the damping function:

- Hypothesis $\zeta_{1}$ : consists on the reduction of the damping function, varying the technical state $\epsilon_{i}$ of the four (4) secondary vertical hydraulic dampers $\delta_{j}$, with $j=1, \ldots, 4$.

- Hypothesis $\zeta_{2}$ : consists on the reduction of the damping function by varying the technical state $\epsilon_{i}$ of the two (2) leading dampers $\left(\delta_{1}, \delta_{2}\right)$, these being the ones located at the closest distance to the driver; the other two (2) dampers $\left(\delta_{3}\right.$, $\left.\delta_{4}\right)$ conserve the nominal property $\epsilon_{10}$.

- Hypothesis $\zeta_{3}$ : consist on the reduction of the damping function by varying the technical state $\epsilon_{i}$ of the two (2) training dampers, these being the ones located at the end opposite to the driver $\left(\delta_{3}, \delta_{4}\right)$; the other two (2) dampers $\left(\delta_{1}, \delta_{2}\right)$ conserve the nominal property $\epsilon_{10}$.

\section{Development of numeric models}

A model of the railway vehicle can be developed and put in motion on a typical track and instrumented in a virtual environment, which allows investigating the effects of a wide range of possible variations of the vehicle parameters $[4,11]$. The results 
obtained from a model can provide accurate predictions of the dynamic behavior of the vehicle and the interaction with the track [20 - 22].

The general approach of a virtual model is to numerically integrate the ordinary differential equation that constitutes the model by using one or various integration algorithms. This approach is usually denominated simulation or numerical experimentation, which is equivalent to physical experimentation where the system is subject to given conditions and its response is registered. This approach is convenient because it [3]:

- allows to different types of models and complexity degree; and

- evaluating the response of any type of perturbation.

But it has limitations such as [3]:

- does not allow identifying the whole behavior of the system, only the response under defined conditions;

- requires computing resources. It generates high computational costs in cases where the system is complex or the model has characteristics that make the numeric integration a difficult procedure; and

- allows the variation effects of the parameters to be predicted, only with a high quantity of simulations.

The numeric model used to simulate the characteristics of the system is considered to be a true virtual prototype. The virtual techniques allow the model to generate information on the dynamic behavior and the interaction of the components, which are only comparable to physical prototypes. Simulations with numeric models are a valid source of the necessary data to apply the formulated methodology. The 
virtual techniques allow the model to generate a great quantity of information not only on response and dynamic behavior, but also relative to the interaction of the components, load details and even aesthetic qualities that are only comparable to physical prototypes $[4,11,12,21]$.

The numeric model developed has 120 DoF [15], the model consist of the union of two (2) simplified models (see Figure 3(a)) and represents a complete motor car (see Figure 3(b)). It is based on the multi-body system theory, using the analysis software VAMPIRE® [23]; the values of the particular parameters of the model are exposed in Appendix 2.

\section{$\{$ Figure 3$\}$}

\section{Test development in a virtual environment}

It is necessary to point out the guidelines for the correct development of the test. The coherent design of the experiment allows a correct analysis of the data and it must be designed to evaluate the secondary suspension under normal operating and controlled conditions, without affecting the operation and the security of the system. The test is defined following these conditions:

- the necessary load condition (AW0), this meaning that the car is empty;

- the section track is straight track and the track irregularities are considered [24];

- the vehicle speed, $\mathrm{V}=80 \mathrm{~km} / \mathrm{h}$; and

- a variation of the secondary suspension dampers technical state is assumed $\epsilon \mathrm{i}$ (see Figure 2 (c)). 
The measurement points are defined according to the railway international standards [25]. Given that the interest of this work focuses on the study of the secondary stage vertical suspension, the signals to be recordered must in the main bodies of the system, in this way three (3) signals in vertical direction are chosen. The signals are located in:

- $\quad \overline{\mathrm{z}}_{\mathrm{q} \mathrm{l}}^{*}$, on the floor of the carbody, at leader side (Error! Reference source not found.(a));

- $\overline{\mathbf{z}}_{\mathrm{qI}}^{*}$, in the bogie frame near to the attack axle (Figure 4(b)); and

- $\bar{z}_{\mathrm{qI}}^{\circ}$, in the axlebox of the attack axle (Error! Reference source not found.(c)).

$\{$ Figure 4\}

\section{Processing and results with the OMA-LSCE method}

The set of signals ${ }^{\bar{z}_{\mathrm{gl}}^{*}},{\overline{\mathbf{Z}_{\mathrm{ql}}}}_{+}^{+}$, and ${ }^{\overline{\mathbf{Z}}_{\mathrm{gl}}^{\circ}}$ is processed by the OMA-LSCE method, based on the measurement of response of the system to the excitations of the operation and from which the global modal parameters are estimated: $\Omega, \xi$ and $\phi$ [12]. The modal parameters are graphically represented by the stabilization diagrams. Appendix 3 exposes as an example a set of stabilization diagrams obtained from different operating conditions of the vehicle. In the diagrams it is possible to identify:

- two (2) local maximums in the range $[1,2.5] \mathrm{Hz}$, which correspond to the two (2) modal shapes (bounce $\phi_{2}$, and pitch $\phi_{4}$ ) and are registered in the carbody by the sensor $\overline{\mathbf{Z}}_{\mathrm{qI}}^{*}$; 
- three (3) local maximums in the range $[4,10] \mathrm{Hz}$, which correspond to the three (3) modal shapes recorded from the bogie by the sensor $\bar{z}_{\mathrm{qI}}^{*}$; and

- three (3) local maximums in the range $[15,25] \mathrm{Hz}$, which correspond to the vertical irregularities of the track and are obtained from the signal registered by sensor $\bar{Z}_{\mathrm{q}}^{\circ}$.

The work focuses on the analysis of the vehicle, more specifically in the carbody for which it has been possible to identify two (2) vertical modal shapes $\left(\phi_{2}\right.$, $\left.\phi_{4}\right)$ under the load condition AW0, see Table 2.

$\{$ Table 2$\}$

\section{Analysis of the results}

From the set of values of the modal parameters identified for the different hypothesis $\zeta_{i}$ it is possible to show the existing relationship between the technical state of the damping set and:

- the natural frequency $\Omega$, of the modal shape $\phi_{2}$ y $\phi_{4}$, obtaining regressive lineal models with a correlation coefficient value of $\sqrt{\mathbf{R}^{2}}>0.98$ (see Figure 5); and

- the damping rate $\xi$, obtaining regressive exponential models with correlation coefficient values of $\sqrt{\mathbf{R}^{2}}>0.96$ (see Figure 6).

The regressive models are considered valid given that the values $\sqrt{\mathbf{R}^{2}}$ represent an association measurement of the statistical model with the obtained data [26], which have an acceptable level for the reach of this work. 
$\{$ Figure 5\}

$\{$ Figure 6$\}$

\section{Validation of the test}

The regressive models belonging to $\zeta_{1}$ and obtained by OMA-LSCE in a virtual environment are extrapolated to the value of the technical state of the damper with a null damping function, $\epsilon_{0}$, for the modal shapes $\phi_{i}$, meaning:

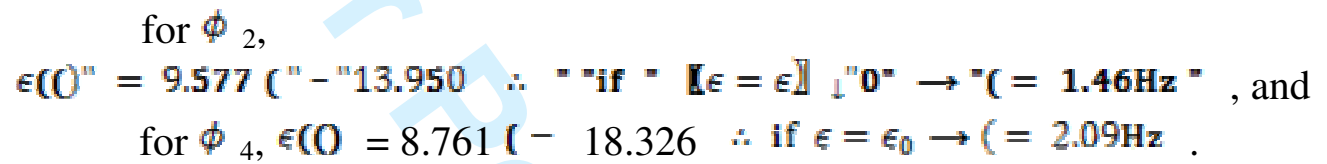

In this way the dynamic behavior of the vehicle without the secondary damper is obtained, emulating the whole extraction of the damping elements of the suspension $\delta_{j}$ with $j=1, \ldots, 4$; which is the same testing condition realized to the vehicle with the EMA technique.

The values reordered by the two (2) types of analysis, EMA and OMA, are compared (see Table 2) which allows observing that there is an estimation error of the modal parameter, $\mathrm{C}^{\mathbf{}}<\mathbf{1 \% "}$. Therefore, it is possible to consider valid the regressive models given that the ( values represent an acceptable deviation level for the reach of this work.

$\{$ Table 3$\}$

\section{Case study, application of the regressive models}

Given the set of signals, $\overline{\bar{z}}_{\mathrm{qI}}^{*}, \overline{\bar{z}}_{\mathrm{qI}}^{+}, \mathrm{y} \overline{\mathrm{z}}_{\mathrm{ql}}^{\circ}$, obtained from a car. The data has been processed through OMA-LSCE, the following identification of modal parameters is obtained: 
- natural frequency: $\Omega=1.53 \mathrm{~Hz}$ for $\phi_{2}$, and $\Omega=2.18 \mathrm{~Hz}$ for $\phi_{4}$; and

- damping rate: $\xi=2.90 \%$ for $\phi_{2}$, and $\xi=2.20 \%$ for $\phi_{4}$.

Starting from the identified modal parameters and based on the series of regressive models obtained for the vehicle, the probable state of the damper is identified $\epsilon_{i}$, for each one of the hypothesis $\zeta_{i}$. The regressive models in the identification of the modal shape $\phi_{2}$ are:

$$
\begin{aligned}
& \text { for } \zeta_{l}, \epsilon\left(O^{n}=9.577\left({ }^{n}-" 13.950 . "{ }^{n} E\left(1.53^{\prime \prime}\right)^{\prime \prime}=" 0.70\right. \text {, }\right. \\
& \epsilon(\xi)=0.084 \mathrm{e}^{0.733 \xi} \quad \therefore \epsilon(2.90)=0.70, \\
& \text { for } \zeta_{2}, \epsilon(\mathrm{O}=13.161(-19.567 \therefore \in(1.53)=0.57 \text {, } \\
& \epsilon(\xi)=0.027 \mathrm{e}^{1.056 \xi} \quad \therefore \epsilon(2.90)=0.58, \\
& \text { for } \zeta_{3}, \epsilon(\mathrm{O}=13.958(-20.873: \epsilon(1.53)=0.48 \text {; } \\
& \epsilon(\xi)=0.008 \mathrm{e}^{1.365 \xi} \quad \therefore \in(2.90)=0.42 \text {; }
\end{aligned}
$$

in the modal shape $\phi_{4}$ are:

$$
\begin{aligned}
& \text { for } \zeta_{1}, \epsilon\left(O^{\prime \prime}=8.761\left("-" 18.326 \therefore " \epsilon(" 2.18 ")^{\prime \prime}=" 0.77\right. \text {, }\right. \\
& \epsilon(\xi)=7.207 \mathrm{E}-5 \mathrm{e}^{4.151 \xi} \quad \therefore \in(2.20)=0.67, \\
& \text { for } \zeta_{2}, \epsilon(\mathrm{O}=23.326(-50.240 \therefore \epsilon(2.18)=0.61 \text {, } \\
& \epsilon(\xi)=1.855 \mathrm{E}-4 \mathrm{e}^{3.773 \xi} \quad \therefore \epsilon(2.20)=0.75, \\
& \text { for } \zeta_{3}, \epsilon(\mathrm{CO}=25.431 \mathrm{C}-54.825: \epsilon(2.18)=0.61 \text {; } \\
& \epsilon(\xi)=5.334 \mathrm{E}-4 \mathrm{e}^{3.279 \xi} \therefore \in(2.20)=0.72 .
\end{aligned}
$$

The $\epsilon$ values from the hypothesis $\zeta_{i}$ are tabulated (Table 4 ). The mean of the technical state is calculated, $\bar{X}_{i}$ as well as their corresponding standard deviation $\sigma_{\mathrm{i}}$, the later will be the criteria that defines the valid hypothesis $\zeta_{t}$. The $\zeta_{i}$ that presents the least standard deviation is the one that adapts to the obtained dynamic characteristics of the system and therefore the value $\bar{X}_{i}$ of such hypothesis must be the technical state of the damper $\epsilon$, meaning $\zeta_{t}=\bar{X}_{i}(\epsilon) \bar{m} \min \left(\sigma_{i}\right)$. 
The technical state of the damper is $\epsilon=\bar{X}(\epsilon) \mp 2 \sigma$ with $95.45 \%$ of confidence factor. For the given case study, the value of the technical state is $\epsilon=0.71 \epsilon_{10} \pm 0.1$ in the four (4) secondary stage vertical dampers (hypothesis $\zeta_{1}$ ) with a confidence of 95.45\%. This means that the dampers are degraded $29 \%$ relative its nominal characteristic.

\section{$\{$ Table 4$\}$}

\section{Conclusions}

The OMA-LSCE technique is a suitable technique to evaluate and identify the technical state of the dampers $\epsilon_{i}$ and the operating characteristics of the components of passengers railway vehicles.

The vertical dampers of the secondary suspension stage present a direct influence on the dynamic behavior of the modal shapes, $\phi_{2}$ and $\phi_{4}$, therefore the different technical states of the damper $\epsilon_{i}$ can be tested and estimated through the dynamic recording in the carbody. This means that from the sensors installed in the carbody that register appropriately the natural frequency $\Omega$ it is possible to determine the variation of the damping function of these elements and to infer their degradation or failure.

The dynamic parameters, $\Omega$ and $\xi$, have a high dependence degree over the secondary suspension dampers $\delta_{j}$.

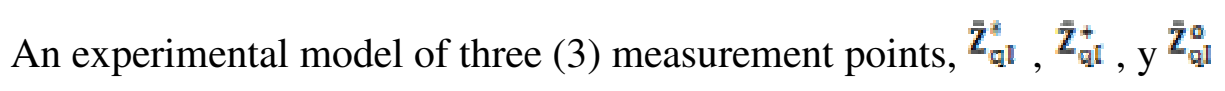
obtained from a set of sensors can be used to identify the dynamic parameters, $\Omega$ and $\xi$, in a vehicle with load condition AW0 with the OMA-LSCE method. 
A methodology has been proposed and applied for the evaluation of the technical state of the dampers and the identification of hypothesis of suspension elements deterioration $\zeta_{i}$ through measurements of variables under operating conditions of the vehicle.

International standards for railway vehicles define the range for deficient frequency $\omega=[8,10] \mathrm{Hz}$. The human body is sensible to vertical accelerations [27]; frequencies $\omega \approx 10 \mathrm{~Hz}$ cause excessive oscillations on $\phi_{2}$, generating significant deficiency of comfort. Comparing with the values obtained for the analyzed vibration modes $\phi_{r}$ and under the different technical states of the damper $\varepsilon_{i}$, the natural frequency is $\Omega<2 \mathrm{~Hz}$. Therefore, the degradation of the damping function of the suspension elements does not incur per se in violation to the railway standard.

\section{Appendix 1. Notation}

\begin{tabular}{|c|c|}
\hline AR & Auto-regression model. \\
\hline AW0 & Anhängerladung Wägestück 0 (load weight 0 ; empty car). \\
\hline DC & Direct Current. \\
\hline DoF & Degrees of Freedom. \\
\hline EMA & Experimental Modal Analysis. \\
\hline FFT & Fast Fourier Transform. \\
\hline FRF & Frequency Response Function. \\
\hline FT & Fourier Transform. \\
\hline IRF & Impulse Response Function. \\
\hline LSCE & Least-Squares Complex Exponential. \\
\hline MAN & Maschinenfabrik Augsburg-Nüernberg. \\
\hline MDoF & Multiple Degrees of Freedom. \\
\hline MIMO & Multiple Input Multiple Output. \\
\hline ODS & Operating Deflection Shapes. \\
\hline OMA & Operational Modal Analysis. \\
\hline FT & Fourier Transform. \\
\hline $\mathrm{RD}$ & Random Decrement process. \\
\hline$\left(i^{\prime \prime} r^{-1}\right)^{-} A^{\prime \prime}+i j$ & $r$ th modal constant. \\
\hline $\mathbf{h}_{\mathrm{k}}$ & $k$ th IRF. \\
\hline $\mathrm{k} \Delta$ & Time interval. \\
\hline $\mathbf{R}^{2}$ & Coefficient of determination. \\
\hline
\end{tabular}


Coefficient of correlation. $r$ th complex quantity root.

$s_{\mathrm{r}}$

$\overline{\mathbf{x}}_{\mathrm{i}} \mathrm{i}=1,2,3 \quad i$ th mean

$\mathrm{V} \quad$ Vehicle speed.

$\mathbf{z}_{\mathrm{r}} \quad$ Conjugacy of the roots $\boldsymbol{s}_{\boldsymbol{r}}$.

$\overline{\mathbf{Z}}_{\mathrm{qI}}^{*}, \overline{\mathbf{Z}}_{\mathrm{qI}}^{*}, \overline{\mathbf{Z}}_{\mathrm{qI}}^{\circ}$ Vertical acceleration at carbody, leader bogie and attack axlebox, respectively.

$\Omega \quad$ Natural frequency.

$\alpha(\omega) \quad$ Receptance matrix

$\beta_{k} \mathbf{k}=0,1, \ldots, 2 k$ th real coefficient.

$\delta_{i} j=1, \ldots, 4 j$ th secondary vertical damper.

$\varepsilon \quad$ Error value.

$\varepsilon_{i} i=1, \ldots, 10 \quad i$ th damper technical state.

$\phi_{\mathrm{r}} \quad r$ th mode shape.

$\sigma_{\mathrm{i}} \mathbf{i}=1,2,3 \quad i$ th standard deviation

$\Omega \quad$ Oscillation frequency.

$\xi \quad$ Damping rate.

$\zeta_{i} i=1,2,3 \quad i$ th hyphotesis

\section{Appendix 2. Vehicle parameters}

$\{$ Table 5\}

\section{Appendix 3. Stabilization diagrams}

$\{$ Figure 7\}

\section{References}

[1] D.J. Ewins, Modal Testing: Theory, Practice and Application, Mechanical Engineering Research Studies Engineering Dynamics Series, Research Studies Press, Second Ed, Hertfordshire, UK, 2000

[2] J. He, and Z.F. Fu, Modal Analysis, Butterworth-Heinemann, UK, 2001.

[3] G. Genta, Vibration Dynamics and Control, Springer Science Business, Torino, Italy, 2009.

[4] L.F. Castañeda, and B. Żółtowski, Estudio de Explotación de vehículos Ferroviarios, Fondo Editorial Universidad EAFIT, Colombia, 2009.

[5] T. Nagayama, M. Abe, Y. Fujino, and K. Ikeda, Structural Identification of a Nonproportionally Damped System and its Application to a Full-Scale Suspension Bridge, Int J. Struct. Eng. 131(2005) pp. 1536-1545.

[6] N.J. Jacobsen, and O. Thorhauge, Data Acquisition Systems for Operational Modal Analysis, IOMAC $-3^{\text {rd }}$ Int. Operational Modal Analysis Conf., Nærum, Denmark, 2009.

[7] N.B. Møller, H. Herlufsen, and S. Gade, Modal Parameters from a Wind Turbine Wing by Operational Modal Analysis', $32^{\text {nd }}$ International Congress and Exposition on Noise Control Engineering, Seogwipo, Korea, 2003. 
[8] E. Yousaf, Output Only Modal Analysis, MSc thesis, Mechanical Engineering Department, Blekinge Institute of Technology, Karlskrona, Sweden, 2007.

[9] N.J. Jacobsen, P. Andersen, and R. Brincker, Using Enhanced Frequency Domain Decomposition as a Robust Technique to Harmonic Excitation in Operational Modal Analysis', ISMA - Int. Conf. on Noise and Vibration Engineering, Leuven, Belgium. 2006.

[10] T. Uhl, and P. Kurowski, Vioma User's Guide, University of Mining and Metallurgy in Kraków Press, Poland, 2002.

[11] K. Goda and R Goodall, Fault-Detection-and-Isolation System for a Railway Vehicle Bogie, in The Dynamics of Vehicles on Roads and on Tracks, M. Abe, ed., Taylor \& Francis, Vol. 41, UK, 2003, pp. 468-476.

[12] T. Uhl, The Inverse Identification Problem and its Technical Application, Springer-Verlag, 2006.

[13] GEMI Research Group, Análisis Modal en Vehículos Ferroviarios Sistema de Transporte Metro de Medellín - , Final Tech. Rep. Mechanical Project Research, EAFIT University, Colombia, 2010.

[14] M.E. Palacio, Implementación de la Norma UIC518 en Vehículos de Pasajeros para el Metro de Medellín, con Énfasis en el Análisis de Ruido Emitido por los Vehículos, M.Sc. thesis, Mechanical Engineering Department, EAFIT University, Colombia, 2006.

[15] R.M. Martinod, L.F. Castañeda, J.A. Gallego, Dynamic Analysis to Evaluate Stability, Safety and Confort in Railway Vehicles, ISPE - $23^{\text {rd }}$ Int. Conf. on CAD/CAM Robotics and Factories of the Future, Colombia, 2007, pp.403408.

[16] UTB, Mediciones Experimentales de Esfuerzos Dinámicos en Marcha. Metro de Medellín, Tech. Rep. Universität Technshe Berlin, Colombia. 1997.

[17] J. Stow, and E. Andersson, Field testing and Instrumentation of Railway Vehicles, in in Handbook of Railway Vehicle Dynamics, S. Iwnicki, ed., Taylor \& Francis, USA, 2006.

[18] C.W. De Silva, Vibration, Fundamentals and Practice, Taylor \& Francis, Second Ed, USA, 2007.

[19] GEMI Research Group, Damper Parameters Analysis of Metro de Medellín, Final Tech. Rep. PV01, Mechanical Project Research, EAFIT University, Colombia, 2009.

[20] R.M. Goodall, and S. Iwnicki, Non-Linear Dynamic techniques v. Equivalent Conicity Methods for Rail Vehicle Stability Assessment, in The Dynamics of Vehicles on Roads and on Tracks, M. Abe, ed., Taylor \& Francis, Vol. 41, UK, 2003, pp. 791-799.

[21] O. Polach, M. Berg, and S Iwnicki, Simulation, in , in Handbook of Railway Vehicle Dynamics, S. Iwnicki, ed., Taylor \& Francis, USA, 2006.

[22] A.H. Wickens, Fundamentals of Rail Vehicle Dynamics. Guidance and Stability, Swets \& Zeitlinger, USA, 2003.

[23] A.J. Minnis, Vampire Product Quality \& Certification, DeltaRail Group Limited, UK, 2007.

[24] K. Knothe, Benchmark Test for Models of Railway Track Ans of Vehicle/Track Interaction in Low Frequency Range, in Iteration of Railway Vehicles whith Track and its Substructure, K. Knothe, S. Grassie, and J. Elkins, eds., Swets \& Zeitlinger, Vol. 24, 1995, pp. 363-379. 
[25] UIC 518, Testing and Approval of Railway Vehicle from the Point of View of Their Dynamic Behaviour - Safety - Track Fatigue - Ride Quality, International Union of Railways, Third Ed, France, 2005.

[26] E.L. Grant, Statistical Quality Control, McGraw Hill, Third Ed, USA, 1964.

[27] ISO 2631-1, Mechanical Vibration and Shock - Evaluations of Human Exposure to whole Body Vibration - Part 4: Guidelines for the Evaluation of the Effects of Vibration and Rotational Motion on Passengers and Crew Comfort of Fixed Guideway Transport Systems, International Standards Organization, Genève, Switzerland, 2001.

[28] D. Thomson, and J. Jones, Noise and Vibration from Raylways Vehicles, in Handbook of Railway Vehicle Dynamics, S. Iwnicki, ed., Taylor \& Francis, USA, 2006. 
Figure 1. Flowchart of the process: (a) Mathematical development; and (b) OMALSCE method.

Figure 2. Railway vehicle: (a) unit of three (3) cars; (b) Location of the secondary dampers; and (c) Damping function of the secondary dampers.

Figure 3: Graphic representation of the numeric models: (a) simple model; and (b) complete model.

Figure 4. Location of the sensors: (a) In the passengers' box $\bar{z}_{\mathrm{qI}}^{*}$; (b) On the bogie $\overline{\mathrm{Z}}_{\mathrm{qI}}^{*}$; and (c) In the axle box $\overline{\mathbf{Z}}_{\mathrm{qI}}^{\circ}$.

Figure 5. Development of regressive models $\zeta$, modal parameter $\Omega$.

Figure 6. Development of regressive models $\zeta$, modal parameter $\xi$.

Figure 7. Estabilization diagrams: (a) Hyphotesis $\zeta_{1}$ with $\epsilon_{1}$; (b) Hyphotesis $\zeta_{1}$ with $\epsilon_{9}$; (c) Hyphotesis $\zeta_{2}$ with $\epsilon_{1}$; (d) Hyphotesis $\zeta_{2}$ with $\epsilon_{9}$; (e) Hyphotesis $\zeta_{3}$ with $\epsilon_{1}$; and (f) Hyphotesis $\zeta_{3}$ with $\epsilon_{9}$. 
Table 1. Modal parameters identify by EMA technique, condition $\epsilon_{0}$.

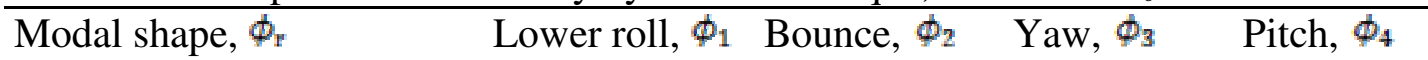

\begin{tabular}{lllll}
\hline Natural frequency, $\Omega[\mathrm{Hz}]$ & 0.80 & 1.47 & 1.50 & 2.10
\end{tabular}


Table 2. Modal parameters identified by OMA-LSCE technique.

\begin{tabular}{|c|c|c|c|c|c|c|c|c|c|c|c|}
\hline \multirow{3}{*}{$\begin{array}{c}\text { Technical } \\
\text { state of } \\
\text { damper, } \\
\epsilon_{i}\end{array}$} & \multicolumn{3}{|c|}{$\zeta_{1}$} & \multicolumn{4}{|c|}{2} & \\
\hline & $\phi_{2}$ & $\phi_{4}$ & 4 & $\phi_{2}$ & 2 & $\Phi$ & $b_{4}$ & $\phi$ & $b_{2}$ & $\phi$ & \\
\hline & $\Omega[\mathrm{Hz}] \xi[\%]$ & $\Omega[\mathrm{Hz}]$ & & $\Omega[\mathrm{Hz}]$ & $\xi[\%]$ & $\Omega[\mathrm{Hz}]$ & & $\Omega[\mathrm{Hz}]$ & $\xi[\%]$ & $\Omega[\mathrm{Hz}]$ & $\xi[\%]$ \\
\hline$\epsilon_{1}$ & 1.4790 .820 & 2.095 & & & & 2.102 & 1.994 & 1.498 & 1.768 & 2.159 & 1.594 \\
\hline$E_{2}$ & 1.4801 .001 & 2.112 & 1.8 & 1.480 & 1.001 & 2.112 & 1.882 & 1.502 & 1.987 & 2.160 & 1.785 \\
\hline$E_{3}$ & 1.4841 .364 & 2.128 & 2.070 & 1.484 & 1.364 & 2.128 & 2.070 & 1.520 & 2.752 & 2.166 & 1.910 \\
\hline$E_{4}$ & 911.8 & 2.144 & 2.136 & 1.491 & 1.876 & 2.144 & 2.136 & 1.526 & 2.745 & 2.170 & 2.037 \\
\hline$E_{5}$ & & 2.159 & & & 2.395 & 2.159 & 2.1 & 1.544 & 3.965 & 2.179 & 2.300 \\
\hline$E_{6}$ & 52.757 & 2.167 & 2.190 & 1.515 & 2.757 & 2.167 & 2.190 & 1.559 & 5.410 & 2.184 & 2.596 \\
\hline$\epsilon_{7}$ & 173.105 & 2.177 & 2.255 & 1.539 & 5.567 & 2.224 & 9.562 & 1.551 & 3.696 & 2.186 & 2.30 \\
\hline$\epsilon_{8}$ & $1.543 \quad 3.239$ & 2.184 & 2.230 & 1.543 & 3.239 & 2.184 & 2.230 & 1.552 & 3.131 & 2.189 & 2.224 \\
\hline$\epsilon_{9}$ & 1.5533 .363 & 2.190 & 2.248 & 1.553 & 3.363 & 2.190 & 2.248 & 1.558 & 3.294 & 2.192 & 2.263 \\
\hline$\epsilon_{10}$ & 1.5613 .449 & 2.195 & 2.273 & 1.561 & 3.449 & 2.195 & 2.273 & 1.562 & 3.511 & 2.196 & 2.322 \\
\hline
\end{tabular}


Table 3. Modal parameters identified by EMA and OMA techniques, condition $\epsilon_{0}$.

\begin{tabular}{lcc}
\hline \multirow{2}{*}{ Modal analysis type } & \multicolumn{2}{c}{ Modal shape $\Omega[\mathrm{Hz}]$} \\
& $\phi_{2}$ & $\phi_{4}$ \\
\hline EMA & 1.47 & 2.10 \\
OMA & 1.46 & 2.09 \\
\hline Error, $\varepsilon[\%]$ & 0.91 & 0.04 \\
\hline
\end{tabular}


Table 4. Evaluation of technical state $\epsilon$ in order to $\zeta_{i}$.

\begin{tabular}{|c|c|c|c|c|c|}
\hline \multirow{2}{*}{ Modal shape, $\phi_{r}$} & \multicolumn{2}{|c|}{ Modal parameter } & \multicolumn{3}{|c|}{ technical state of damper $\epsilon[--]$} \\
\hline & Description & Value & $\zeta_{1}$ & $\zeta_{2}$ & $\zeta_{3}$ \\
\hline \multirow[b]{2}{*}{$\phi_{2}$} & $\Omega[\mathrm{Hz}]$ & 1.53 & 0.70 & 0.57 & 0.48 \\
\hline & $\xi[\%]$ & 2.90 & 0.70 & 0.58 & 0.42 \\
\hline \multirow{2}{*}{$\phi_{4}$} & $\Omega[\mathrm{Hz}]$ & 2.18 & 0.77 & 0.61 & 0.61 \\
\hline & $\xi[\%]$ & 2.20 & 0.67 & 0.75 & 0.72 \\
\hline \multicolumn{3}{|l|}{ Mean value, $\overline{\mathbf{x}}_{\mathrm{i}}$} & 0.71 & 0.63 & 0.56 \\
\hline \multicolumn{3}{|c|}{ Standard deviation, $\sigma_{i}$} & 0.04 & 0.08 & 0.14 \\
\hline
\end{tabular}


Table 5. Vehicle parameters.

\begin{tabular}{|c|c|c|c|}
\hline Element & Quantity & Value & Unit \\
\hline \multicolumn{4}{|l|}{ Mass } \\
\hline Carbody & 1 & 24486.36 & $\mathrm{~kg}$ \\
\hline Bogie frame & 2 & 6102.44 & $\mathrm{~kg}$ \\
\hline Motor & 4 & 5551 & $\mathrm{~kg}$ \\
\hline Electromag. brake & 4 & 704 & $\mathrm{~kg}$ \\
\hline Traction link & 2 & -- & $\mathrm{kg}$ \\
\hline Axle-wheel set & 4 & 7083.52 & $\mathrm{~kg}$ \\
\hline \multicolumn{4}{|l|}{ Stiffness } \\
\hline Lineal & 1 & $\mathrm{k}_{\mathrm{A}}=1.00$ & $\mathrm{kN} / \mathrm{mm}$ \\
\hline Non-lineal & 20 & -- & $\mathrm{kN} / \mathrm{mm}$ \\
\hline \multirow[t]{3}{*}{ Shear } & 8 & $\mathrm{k}_{\mathrm{x}}=2.16$ & $\mathrm{kN} / \mathrm{mm}$ \\
\hline & & $\mathrm{k}_{\mathrm{y}}=2.16$ & $\mathrm{kN} / \mathrm{mm}$ \\
\hline & & $\mathrm{k}_{\mathrm{z}}=12.16$ & $\mathrm{kN} / \mathrm{mm}$ \\
\hline Axi-directional & 2 & 0.08 & $\mathrm{kNmm} / \mathrm{s}$ \\
\hline \multirow[t]{2}{*}{ Air stiffness } & 4 & $\mathrm{k}_{\mathrm{z}}=4.52$ & $\mathrm{kN} / \mathrm{mm}$ \\
\hline & & $\mathrm{k}_{\mathrm{y}}=1.04$ & $\mathrm{kN} / \mathrm{mm}$ \\
\hline Non-lineal damper & 13 & -- & $\mathrm{kNmm} / \mathrm{s}$ \\
\hline Busing & 36 & $\mathrm{k}_{\mathrm{x}}=67.32$ & $\mathrm{kN} / \mathrm{mm}$ \\
\hline & & $\mathrm{k}_{\mathrm{y}}=36 \mathrm{E}-5$ & $\mathrm{kN} / \mathrm{mm}$ \\
\hline
\end{tabular}




\begin{tabular}{cccc}
\hline Element & Quantity & Value & Unit \\
& & $\mathrm{k}_{\mathrm{z}}=72 \mathrm{E}-6$ & $\mathrm{kN} / \mathrm{mm}$ \\
& $\mathrm{k}_{\theta}=36 \mathrm{E}-5$ & $\mathrm{MNm} / \mathrm{rad}$ \\
& $\mathrm{k}_{\phi}=2 \mathrm{E}-6$ & $\mathrm{MNm} / \mathrm{rad}$ \\
& & $\mathrm{k}_{\psi}=1 \mathrm{E}-5$ & $\mathrm{MNm} / \mathrm{rad}$ \\
& & & -- \\
DOF & 120 & & -- \\
Conicity non-lineal & & & - \\
\hline
\end{tabular}




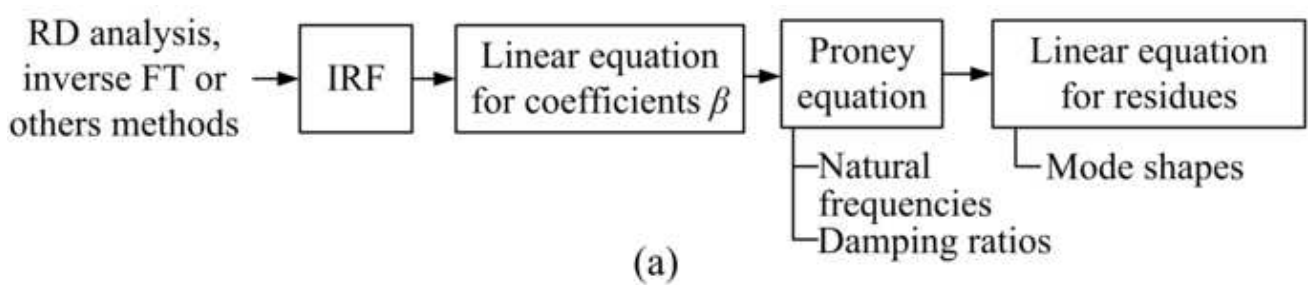

$28 \times 6 \mathrm{~mm}(600 \times 600 \mathrm{DPI})$ 
(b)

$29 \times 6 \mathrm{~mm}(600 \times 600 \mathrm{DPI})$ 


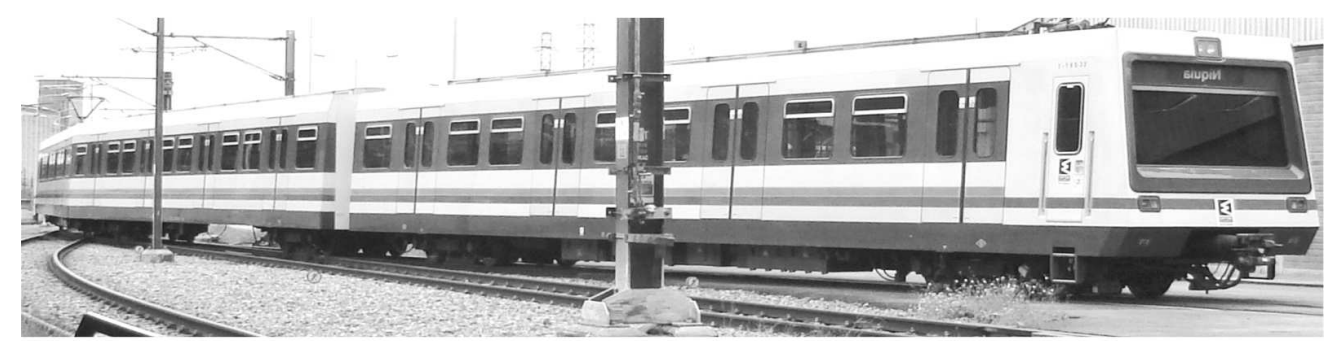

(a)

$135 \times 38 \mathrm{~mm}(600 \times 600 \mathrm{DPI})$ 


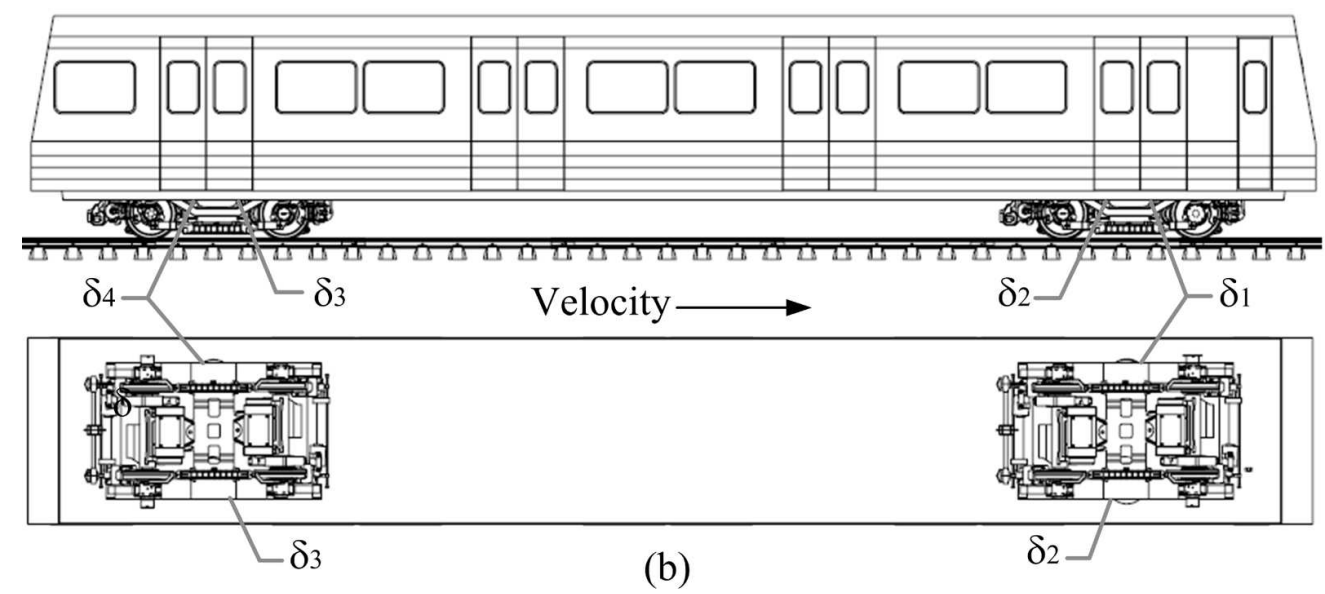

$135 \times 61 \mathrm{~mm}(600 \times 600 \mathrm{DPI})$ 


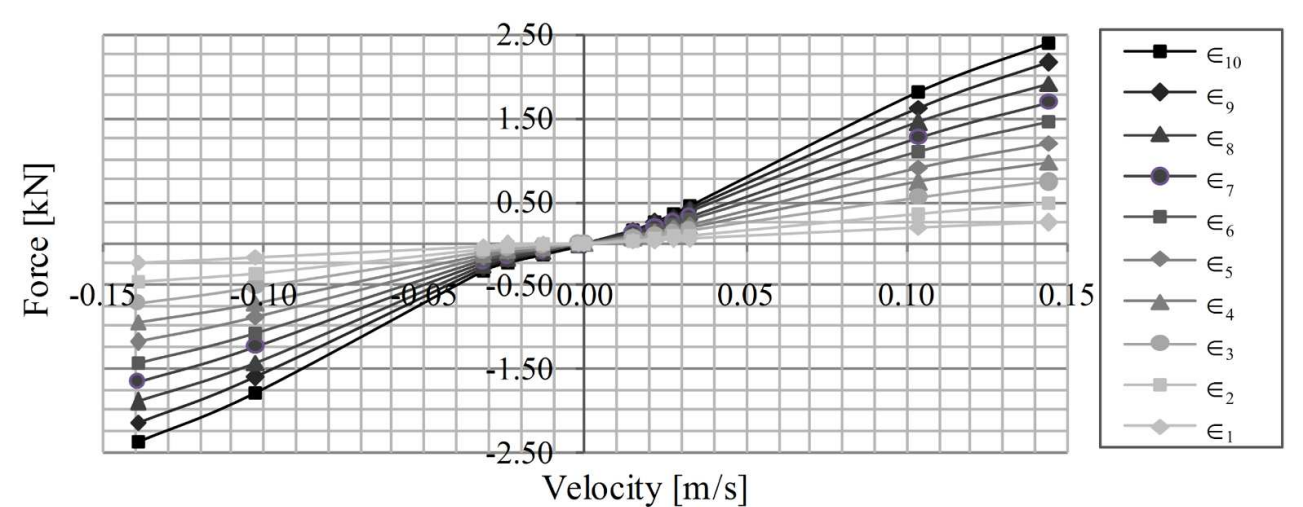

(c)

$135 \times 56 \mathrm{~mm}(600 \times 600 \mathrm{DPI})$ 


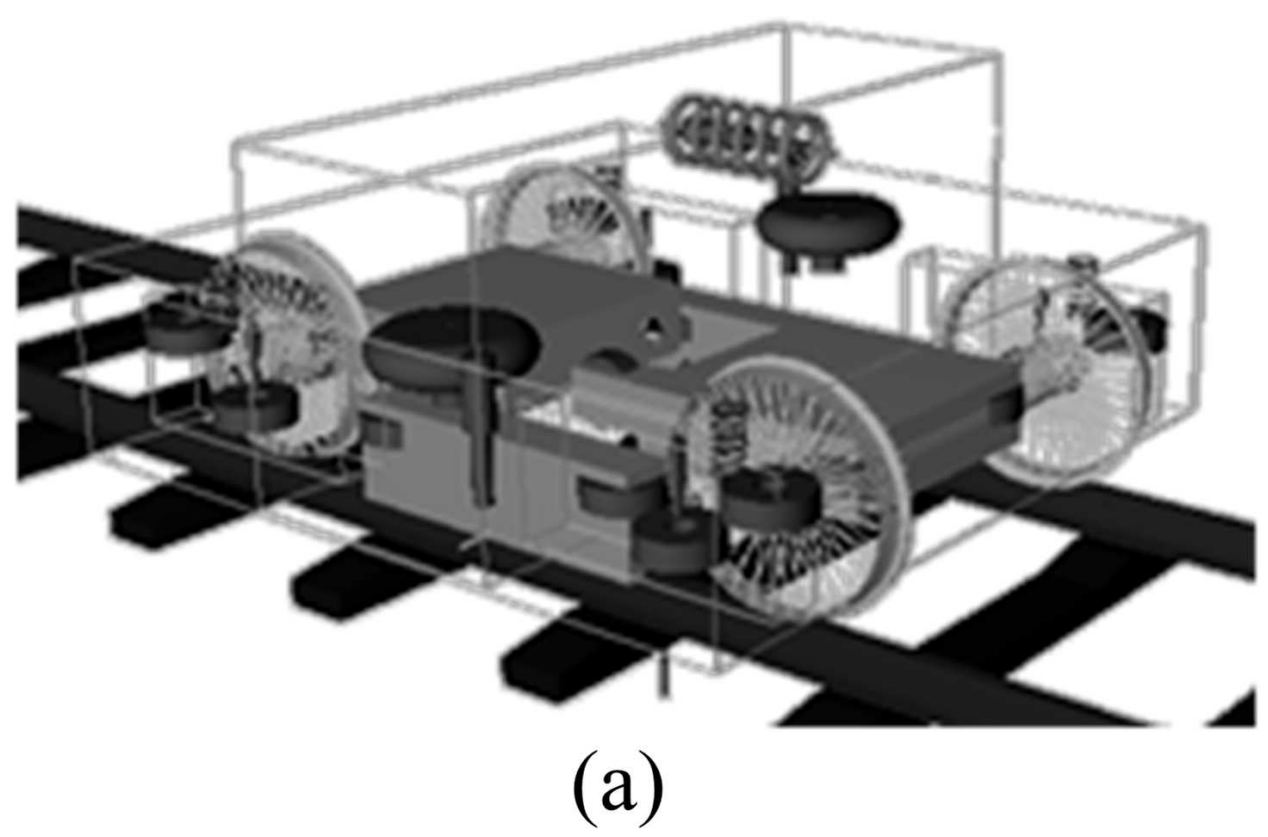

$64 \times 41 \mathrm{~mm}(600 \times 600 \mathrm{DPI})$ 


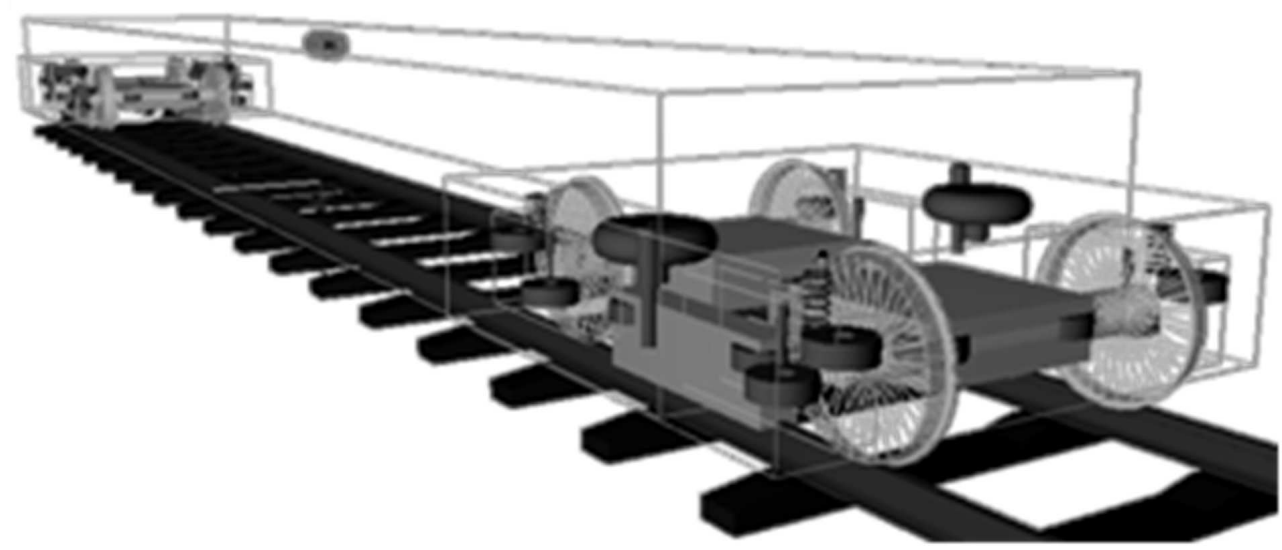

(b)

$82 \times 41 \mathrm{~mm}(600 \times 600 \mathrm{DPI})$ 


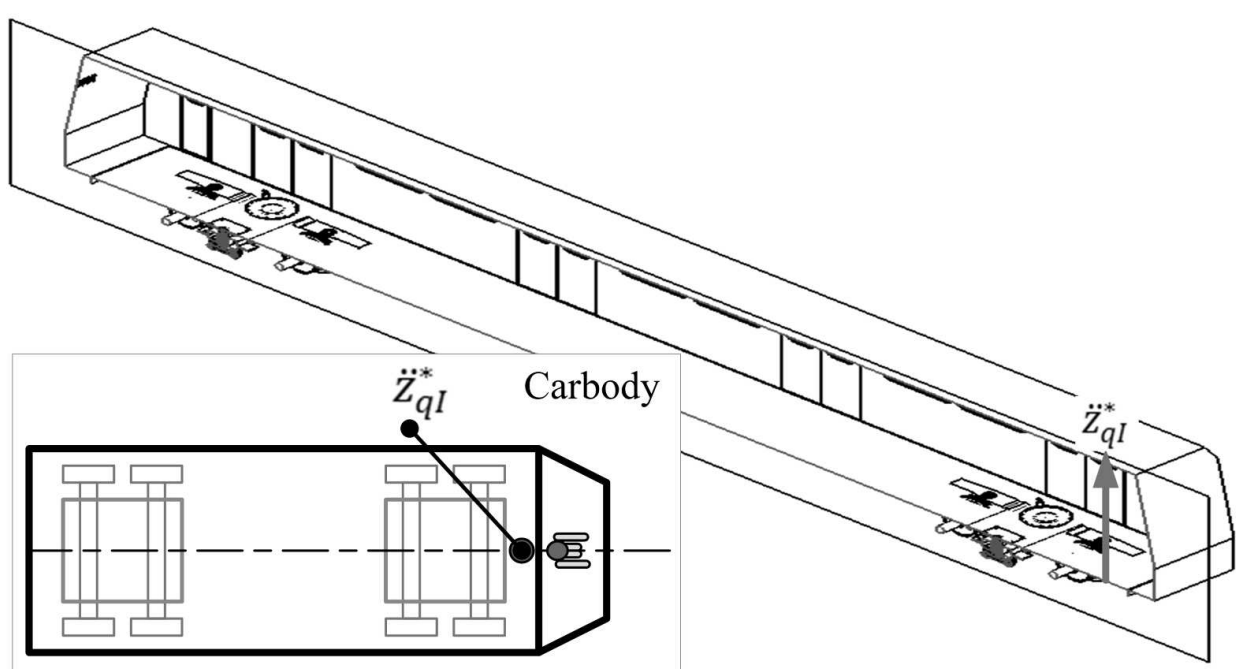

(a)

$139 \times 77 \mathrm{~mm}(600 \times 600 \mathrm{DPI})$ 


1
2
3
4
5
6
7
8
9
10
11
12
13
14
15
16
17
18
19
20
21
22
23
24
25
26
27
28
29
30
31
32
33
34
35
36
37
38
39
40
41
42
43
44
45
46
47
48
49
50
51
52
53
54
55
56
57
58
60

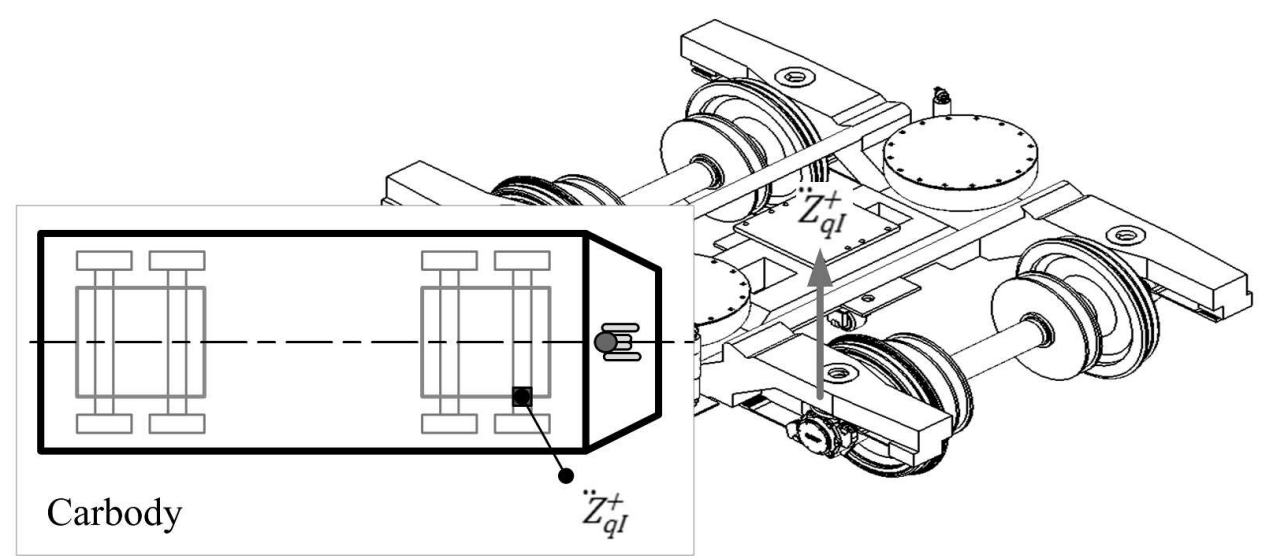

(b)

$139 \times 64 \mathrm{~mm}(600 \times 600 \mathrm{DPI})$ 


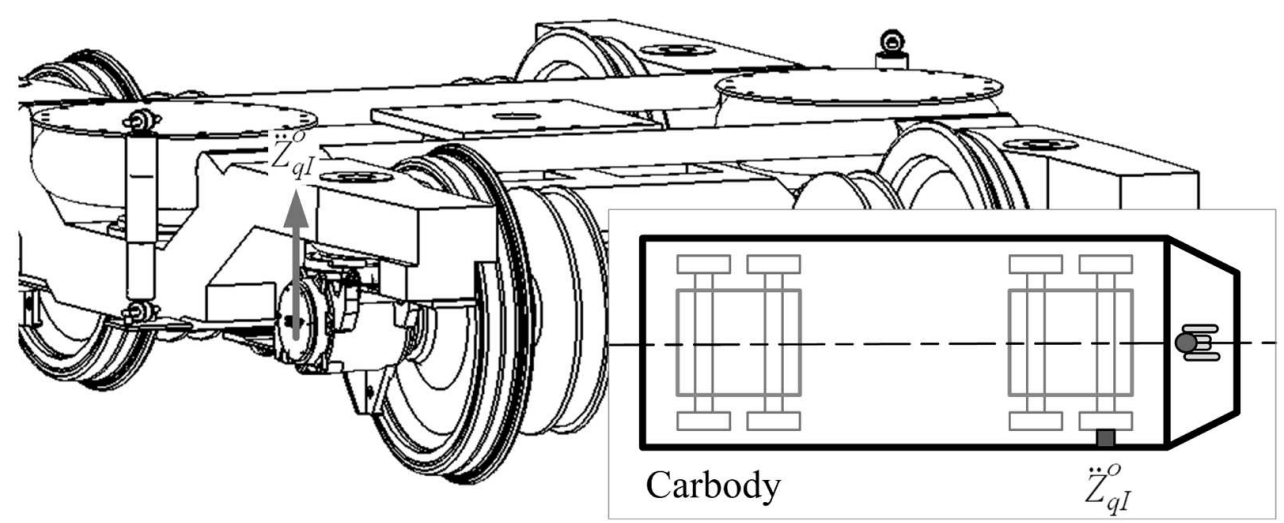

(c)

$139 \times 59 \mathrm{~mm}(600 \times 600 \mathrm{DPI})$ 

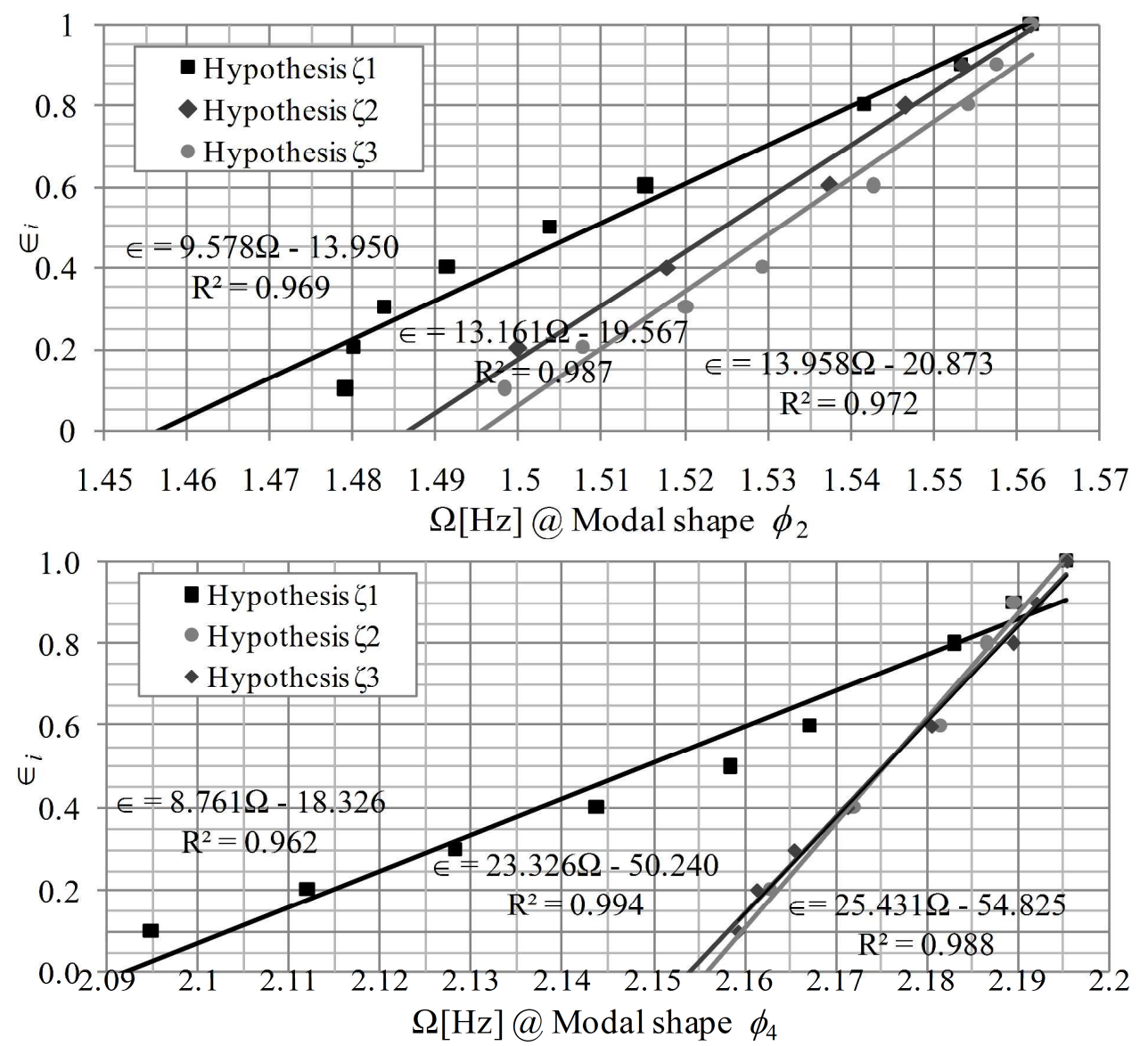

$167 \times 151 \mathrm{~mm}(600 \times 600 \mathrm{DPI})$ 

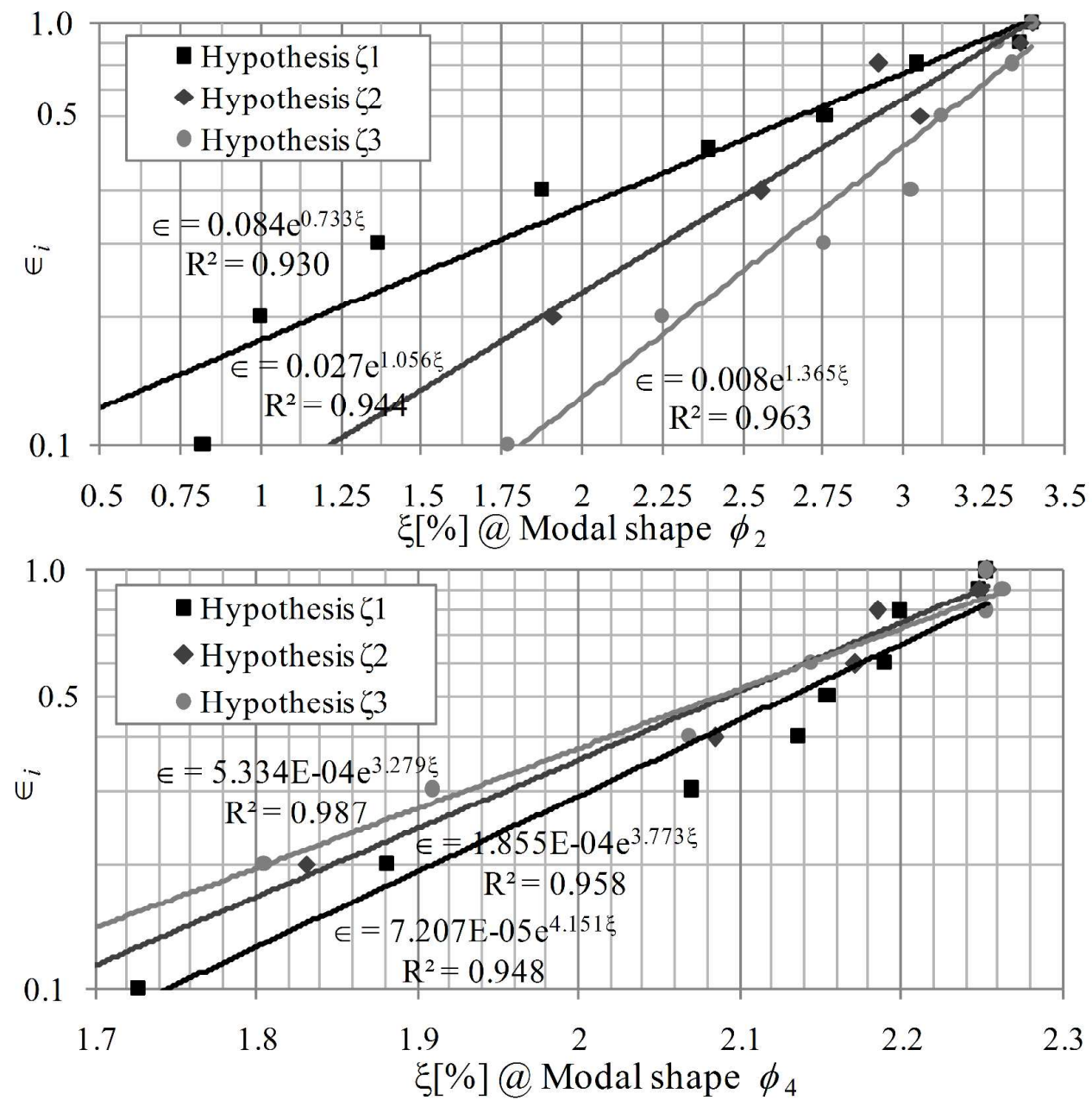

$143 \times 141 \mathrm{~mm}(600 \times 600 \mathrm{DPI})$

URL: http://mc.manuscriptcentral.com/nvsd 


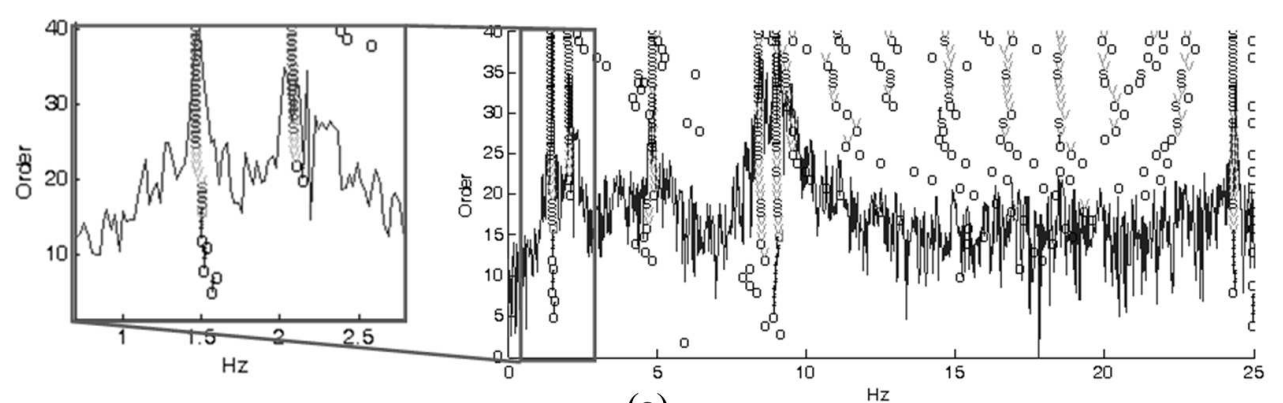

(a)

$139 \times 45 \mathrm{~mm}(600 \times 600$ DPI $)$ 


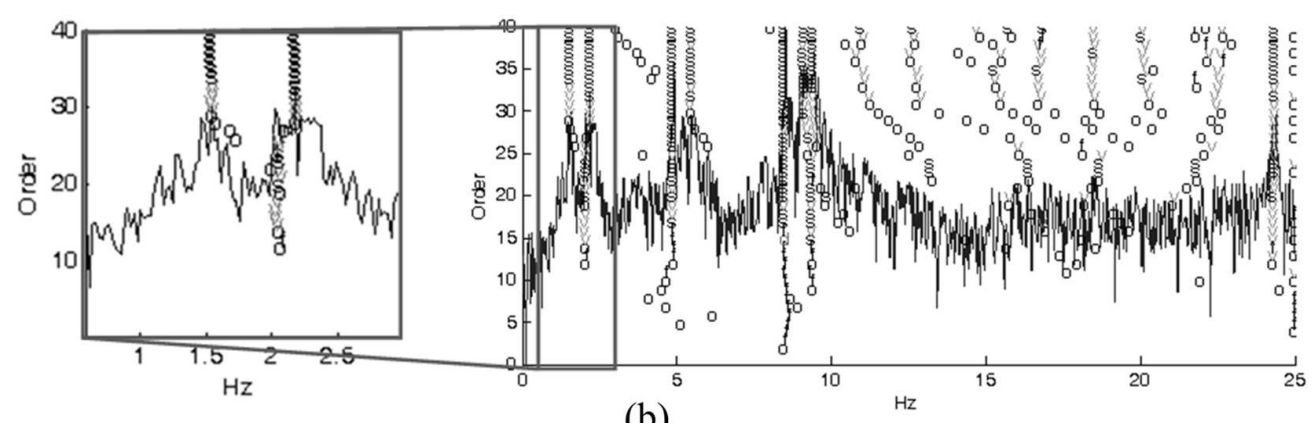

(b)

$140 \times 46 \mathrm{~mm}(600 \times 600 \mathrm{DPI})$ 
Page 41 of 44

Vehicle System Dynamics

\begin{tabular}{l}
1 \\
2 \\
3 \\
4 \\
5 \\
6 \\
7 \\
8 \\
9 \\
10 \\
11 \\
12 \\
13 \\
14 \\
15 \\
16 \\
17 \\
18 \\
19 \\
20 \\
21 \\
22 \\
23 \\
24 \\
25 \\
26 \\
27 \\
28 \\
29 \\
30 \\
31 \\
32 \\
33 \\
34 \\
35 \\
36 \\
37 \\
38 \\
39 \\
40 \\
41 \\
42 \\
43 \\
44 \\
45 \\
46 \\
47 \\
48 \\
59 \\
50 \\
51 \\
52 \\
5 \\
\hline
\end{tabular}

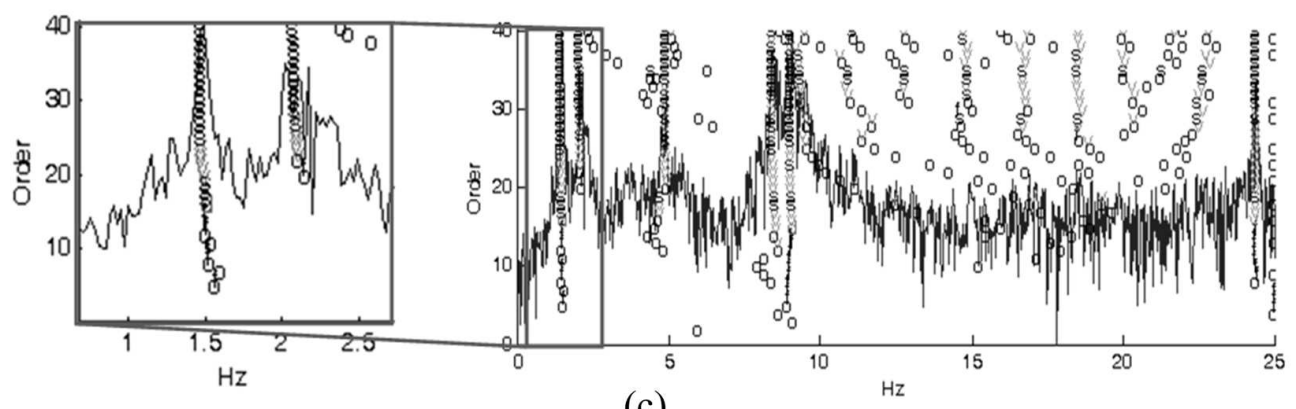

(c)

$139 \times 46 \mathrm{~mm}(600 \times 600 \mathrm{DPI})$

URL: http://mc.manuscriptcentral.com/nvsd 


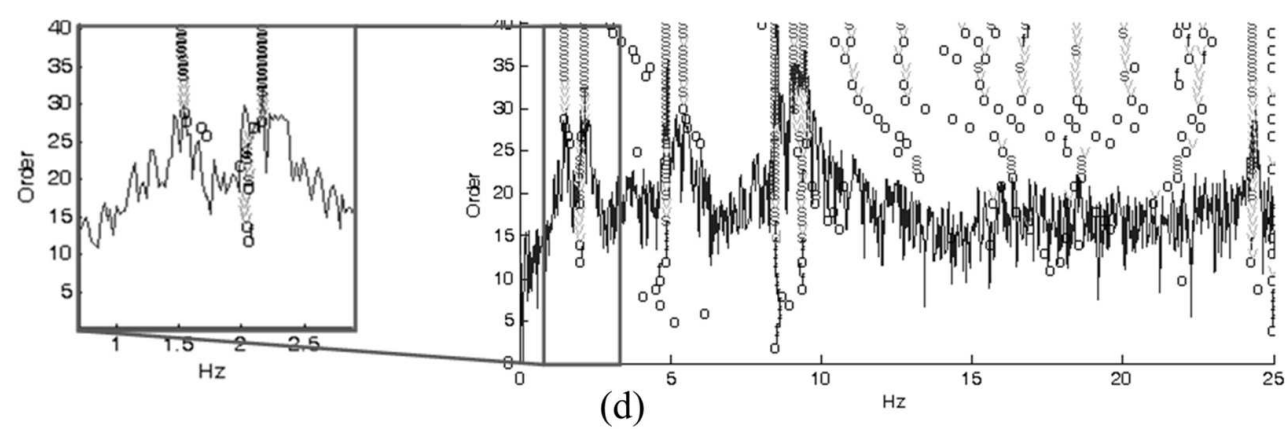

$140 \times 45 \mathrm{~mm}(600 \times 600 \mathrm{DPI})$ 


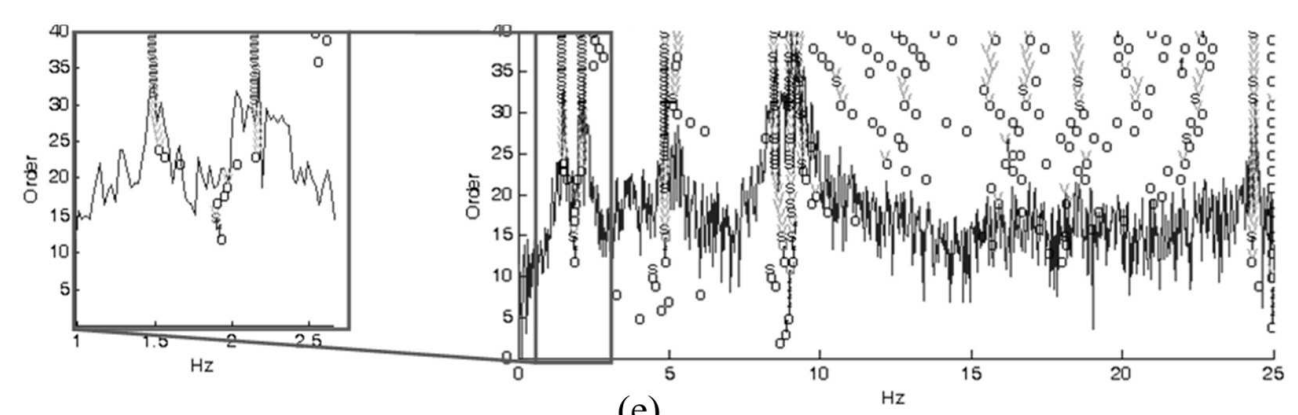

(e)

$140 \times 44 \mathrm{~mm}(600 \times 600 \mathrm{DPI})$ 


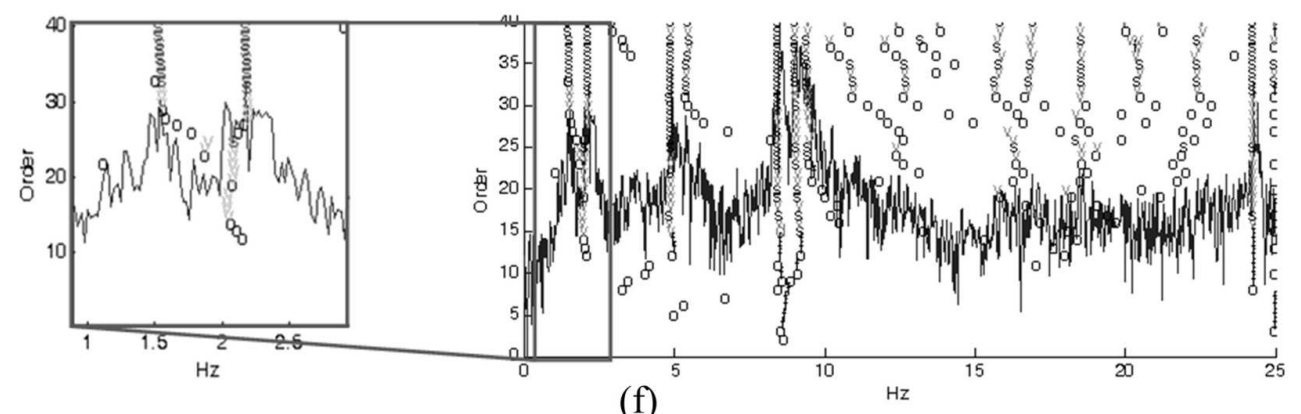

(f)

$141 \times 45 \mathrm{~mm}(600 \times 600 \mathrm{DPI})$ 